\title{
C-type natriuretic peptide in reproduction, pregnancy and fetal development
}

\author{
T Walther and H Stepan ${ }^{1}$ \\ Department of Cardiology and Pneumology, Free University of Berlin, Germany \\ ${ }^{1}$ Department of Obstetrics and Gynecology, University of Leipzig, Germany \\ (Requests for offprints should be addressed to H Stepan, Universitätsfrauenklinik, Philipp-Rosenthalstr 55, 04103 Leipzig, Germany; \\ Email: steh@medizin.uni-leipzig.de)
}

\begin{abstract}
C-type natriuretic peptide (CNP) belongs to the natriuretic peptide family that consists of three structurally related peptides with a 17 -amino acid ring linked by a disulfide bond. In contrast to atrial and brain natriuretic peptides that are mainly cardiovascular hormones, CNP acts predominantly in an autocrine/paracrine fashion, is commonly considered to be an endothelial hormone with antimitogenic properties, and is characterized as a regulator of endochondral ossification. Its biological effects are mediated by an intracellular cGMP accumulation via specific membrane-bound guanylyl cyclase B (GC-B) activation. There is growing evidence that this peptide is also involved in various reproductive processes as well as in embryonic and fetal development. In rodents, CNP and its receptor are highly expressed in the uterus and ovaries with specific regulation during the estrous cycle. During pregnancy, CNP mRNA is detectable in mice embryos and shows an organ-specific expression in maternal reproductive tissues with the highest concentration in the placenta. This could indicate a defined biological function
\end{abstract}

of the CNP/GC-B/cGMP axis in gestation e.g. antagonizing vasoconstrictive peptides like angiotensin II. In humans, besides a postulated fetal de novo synthesis of CNP, both the peptide and its receptor are expressed in the placenta and myometrium with opposite regulation of CNP in pregnancies complicated by pre-eclampsia or intrauterine growth retardation. Since the maternal plasma levels do not reflect these alterations, one can conclude that this part of the natriuretic peptide system acts locally suggesting that CNP-stimulated cGMP release exhibits organ-specific effects.

Importantly, CNP has also become a peptide with a distinct role in male reproductive processes, since endocrine function of the testis and the regulation of penile erection are regulated by the CNP/GC-B axis. This review gives a comprehensive overview of the multiple functions of CNP in reproduction and pregnancy as well as in embryonic and fetal development.

Journal of Endocrinology (2004) 180, 17-22

\section{Introduction}

The natriuretic peptide family consists of three structurally related peptides: atrial natriuretic peptide (ANP), brain natriuretic peptide (BNP), and C-type natriuretic peptide (CNP) (Levin et al. 1998). These peptides can influence a variety of homeostatic processes by the intracellular accumulation of cyclic GMP (cGMP) through two different membrane-bound guanylyl cyclase (GC)-coupled receptors (GC-A and GC-B) (Koller \& Goeddel 1992). ANP and BNP are cardiac hormones that are produced predominantly by the atrium and ventricle respectively, and are thought to play an important role in the regulation of cardiovascular homeostasis (Maack 1996, Ganguly et al. 1999, Stein \& Levin 1998). In contrast, CNP occurs in a wide variety of tissues (Komatsu et al. 1991, Heublein et al. 1992, Totsune et al. 1994, Stepan et al. 2000a), where it may act locally as an autocrine/paracrine regulator through GC-B. Moreover, CNP is regarded as the 'endothelial component' of the natriuretic system and a local positive regulator of endochondral ossification (Chen \& Burnett 1998, Chusho et al. 2001).

Two pathways have been described for the clearance of circulating natriuretic peptides: binding and internalization via the natriuretic peptide clearance receptor (Maack et al. 1987) and enzymatic degradation by neutral endopeptidase (EC $3 \cdot 4 \cdot 24 \cdot 11$ ), a widespread zinc metallopeptidase that cleaves several peptide hormones by hydrolyzing internal peptide bonds at the amino side of hydrophobic residues (Kenny et al. 1993). 


\section{inactive \&...... ANP \\ fragments BNP
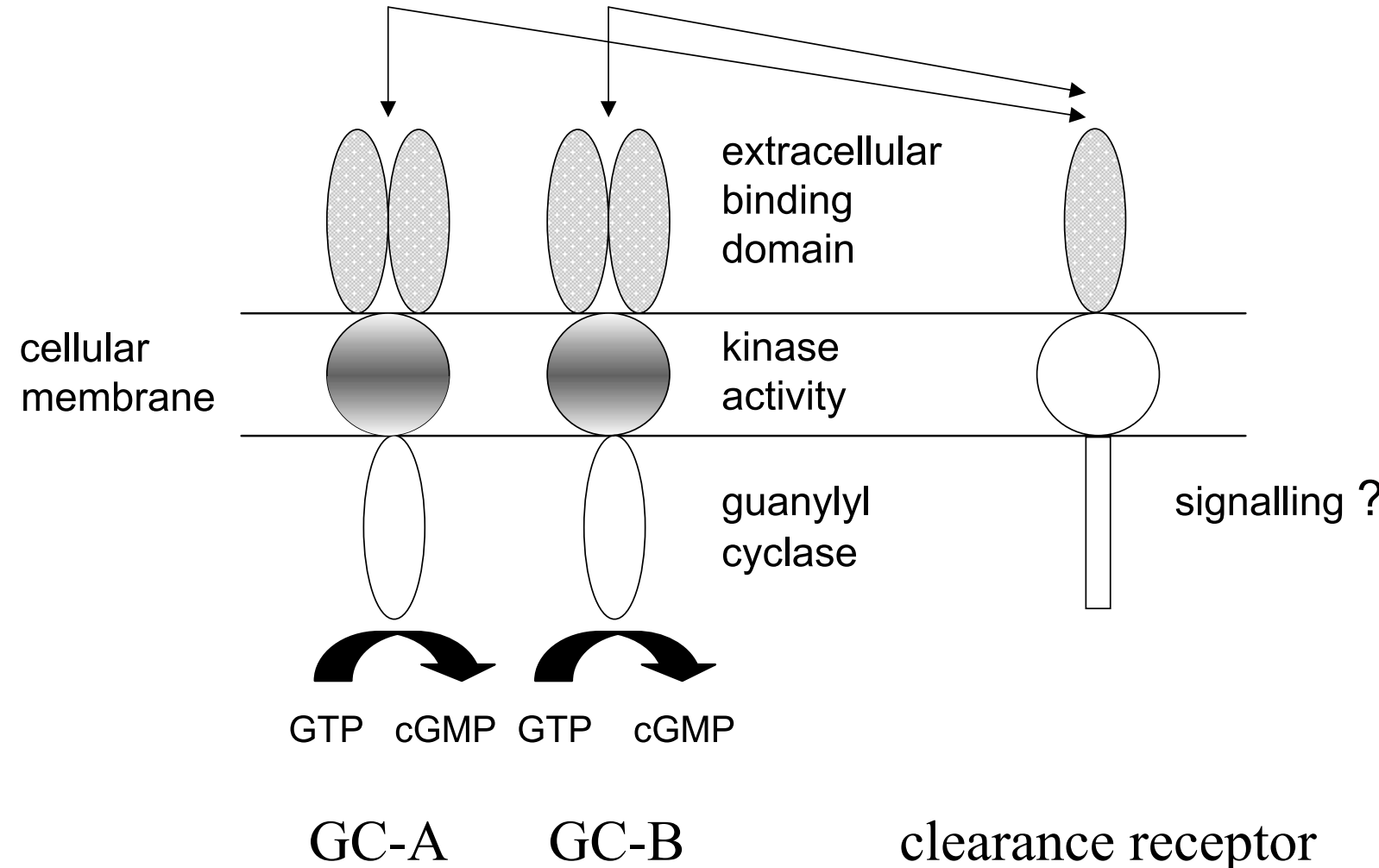

clearance receptor

Figure 1 Schematic organization of the natriuretic peptide system (binding and degradation) with the three natriuretic peptides, two functional receptors and a clearance receptor without its own intracellular signaling. The scheme also shows the dual structure consisting of ANP-BNP/GC-A/CGMP and CNP/GC-B/CGMP.

A number of studies have shown that the natriuretic peptide system (NPS) can be divided into two axes with ANP and BNP (via GC-A) on one side and CNP (via GC-B) on the other (Fig. 1). Moreover, the ANP/BNP axis is not equally regulated but shows a functional dualism exhibiting different responses to various stimuli such as cardiac filling pressure (Yoshimura et al. 1993, Walther et al. 2001). Besides the cardiovascular as well as the endothelial functions of CNP, there are numerous hints of a biologically relevant role of this peptide in reproduction and fetal development: (1) in adult mice, the uterus and ovaries show the highest CNP expression (Stepan et al. 2000a); (2) estradiol induces CNP gene expression at least in the mouse uterus (Acuff et al. 1997); (3) CNP and its receptor are expressed in rat placenta (Cameron et al. 1996) and are modulated in rat ovary and uterus by the estrous cycle, with maximal expression at proestrus (Dos Reis et al. 1995, Huang et al. 1996); (4) for human reproductive tissues, it can be demonstrated that CNP expression is altered in pathological states of pregnancy such as intrauterine growth retardation (IUGR) (Stepan et al. 2002a); and (5) in the male reproductive system, CNP is involved in the regulation of testicular and erectile function (Middendorff et al. 2000, Küthe et al. 2003). Therefore, the aim of this review is to provide a comprehensive overview of the multiple functions of CNP in reproduction and pregnancy as well as in embryonic and fetal development.

\section{CNP in female reproductive tissues}

Following the first description of CNP in the porcine brain (Sudoh et al. 1990) and its characterization as a neurotransmitter and cardiovascular peptide (Clavell et al. 1993), the first hints regarding a possible function of CNP in reproduction were described. In non-pregnant mice, the uterus and ovaries are the organs with the highest CNP mRNA concentrations, exceeding the CNP levels of organs such as the brain or kidney (Stepan et al. 2000a). Detailed investigations showed that the uterine CNP expression is obviously controlled by other 
hormone systems. For instance, an intraperitoneal infusion of estradiol increases uterine CNP in a dose-dependent fashion in ovariectomized mice (Acuff et al. 1997). In rats, uterine CNP content is modulated by the estrous cycle with the highest expression at proestrus (Huang et al. 1996). This cycle dependency can result from uterine mass and fluid content changes or from estradiol variations (Acuff et al. 1997). The regulation of CNP in reproductive tissues from non-pregnant animals occurs in parallel with a high expression of the CNP receptor (GC-B), and is, for example, a hundred times higher in the uterus compared with the GC-A receptor (Dos Reis et al. 1995). Also in the rat ovary, both CNP and GC-B show a time-dependent expression over the estrous cycle (Jankowski et al. 1997). As far as the role of the $\mathrm{CNP} / \mathrm{GC}-\mathrm{B}$ axis in the ovary is concerned, a modulation of follicular atresia through CNP has been postulated. McGee et al. (1997) showed that 8-bromo-cGMP, an inhibitor of the guanylyl cyclase signaling, was able to decrease follicular atresia, which appears mainly in follicles at the preantral to antral transition. Beside the regulated expression of CNP and its receptor, these findings point indirectly to a physiological role of the NPS, particularly CNP, in female reproductive organs.

\section{CNP in male reproductive tissues}

The further characterization of CNP has provided more and more evidence that this hormone is also involved in male reproductive processes. Both CNP and its receptor are expressed in human testis (Middendorff et al. 1997, 2000). It was demonstrated that the factor in porcine seminal plasma that causes an increase in cGMP was indeed CNP (Chrisman et al. 1993). The third member of the NPS also influences testicular endocrine function such as testosterone release via cGMP, and is also involved in the regulation of Leydig and Sertoli cell function (Middendorff et al. 1997, 2000). Possible paracrine actions include relaxation of seminiferous tubules in order to regulate sperm transport and testicular blood supply respectively (Middendorff et al. 1997). Thus, the CNP/ GC-B/cGMP cascade leads to a variety of biological effects in the testis such as modulating spermatozoa motility, testicular germ cell development and testosterone synthesis (Middendorff et al. 2000).

Since sildenafil, an inhibitor of the cGMP-degrading phosphodiesterase type 5 , has been introduced into broad clinical practice, it has become clear that cGMP-mediated processes not only regulate autocrine/paracrine testicular functions, but also have an impact on erectile function. This has been supported by the observation that in rabbits and rats CNP binds to the GC-B receptor of the cavernosal membrane and causes smooth muscle cell relaxation within the penis (Kim et al. 1998), and by the finding of Küthe et al. (2003) that the GC-B receptor is expressed in the human corpus cavernosum, suggesting that CNP influences penile erection. Furthermore, there is an observed cross-talk between the CNP/GC-B axis and the receptors of cAMP elevating peptides such as vasoactive intestinal peptide and pituitary adenylate cyclase activating peptide in regulating erectile function (Guidone et al. 2002). In conclusion, CNP has an impact on the biological function of the male reproductive tract regarding endocrine testicular regulation and penile erection.

\section{Maternal CNP regulation during pregnancy}

Pregnancy induces a 38-fold increase in uterine cGMP production (Itoh et al. 1998), indicating activation, besides other cGMP-generating systems such as the kallikreinkinin system, especially of the NPS. In mice, uterine CNP mRNA concentrations increase up to sevenfold during pregnancy, whereas in the ovaries these levels decrease to ten percent of those of non-pregnant controls (Stepan et al. 2001). These reciprocal and gestational age-dependent changes of CNP expression have led to hypotheses about the biological control and functions of CNP during pregnancy. First, the ability of CNP to relax smooth muscle cells may have a protective effect during gestation by inhibiting uterine contractions (Drewett et al. 1995). Interestingly, the natriuretic peptide-induced relaxation seems to be independent of cGMP, since blockage of guanylyl cyclase A or B activation did not diminish this effect in the myometrium (Carvajal et al. 2001). Shear stress, a CNP-inducing factor (Okahara et al. 1995), caused the observed CNP increase within the growing uterus. Moreover, since CNP is produced in the thecainterstitium, which is under luteinizing hormone (LH) control (Jankowski et al. 1997), the decrease in ovarian CNP expression with advancing gestational age may result from a lack of $\mathrm{LH}$ stimulation.

Using in situ-hybridization, Cameron et al. (1996) showed a strong placental CNP expression in mice starting at day 10.5 post coitus (pc), with the strongest expression localized around the large maternal blood vessels. Our group detected CNP mRNA in murine placentas from day $9 \cdot 5 \mathrm{pc}$ with a maximum at day $15 \cdot 5 \mathrm{pc}$ (Stepan et al. 2001). Thus, the course of placental CNP expression is similar to that of ANP, which peaks at day 16 in rats (Huang et al. 1992). The direct comparison of CNP expression between placenta, uterus, and ovaries showed that the placental CNP mRNA concentration exceeds that of the uterus and ovary. The concept of a functioning local NPS in the placenta is further supported by the finding that both GC-A and GC-B are expressed in the human placenta at term (Hatjis \& Grogan 1988, Itoh et al. 1994), and their expression patterns change greatly during pregnancy. Whereas the clearance receptor is downregulated, the soluble and particulate guanylyl cyclases 
increase specifically in the ovine uterine but not systemic arteries (Itoh et al. 1998).

CNP mRNA was detected in human placenta and myometrium. In these tissues CNP expression levels did not differ between term and preterm pregnancies (Stepan et al. 2002a). Pregnancies with IUGR or pre-eclampsia show an opposite regulation of CNP with a decrease in the placenta and an increase in the myometrium compared with normal pregnancies; this could indicate a compensatory or causative organ-specific function of the peptide in human reproductive tissue under these pathophysiological conditions (Stepan et al. 2002a,b). Interestingly, both pregnancy disorders are a clinical consequence of placental insufficiency and are characterized by comparable CNP expression pattern in the placenta and myometrium. However, in contrast to CNP, BNP at the protein level is up-regulated in the placenta of pre-eclamptic patients (Walther et al. 2002) indicating different functions for the two NPS axes.

Interestingly, maternal CNP plasma levels were not influenced by the IUGR situation or in pregnancies with hypertensive disorders such as pregnancy-induced hypertension or pre-eclampsia (Stepan et al. 1998a, 1999, 2002a), emphasizing that in the above mentioned tissue CNP regulation does not reflect the circulating peptide concentrations. However, other factors can influence maternal peripheral CNP concentrations. For instance, CNP is significantly increased after volume load before cesarean section (Stepan et al. 1998b), which leads to the postulate that systemic CNP release can be triggered by rapid volume expansion, as is typical for ANP. Animal models support this concept of a systemic CNP response to volume (Borgeson et al. 1998). Secondly, CNP is significantly up-regulated in labor (Stepan et al. 1998b), which could be related to a known interaction between CNP and catecholamines that are increased during uterine contractions (Vatta et al. 1997).

Further studies will prove whether NT-proCNP(1-50), the biologically inactive fragment of the CNP precursor which is increased in human patients with congestive heart failure (Prickett et al. 2001), may better reflect the local changes due to its longer half-life.

\section{CNP and fetal development}

A number of studies have described early expression of CNP in embryonic and fetal tissues, indicating that this component of the NPS has functions during the first stages of intrauterine development. Using in situ-hybridization, CNP mRNA could be detected in distinct areas of the mouse brain at day $10.5 \mathrm{pc}$ (in the ventricular zone of the pons adjacent to the floor of the fourth ventricle and in the cerebral cortex) and in the spinal cord (Cameron et al. 1996). Our group was able to detect CNP mRNA in both head and trunk of mouse embryos. For both parts of the embryo, high mRNA concentrations were found at day
$9 \cdot 5 \mathrm{pc}$ with no significant difference between the head and trunk; this was followed by a significant decrease. A further peak in the heads of embryos was visible at day $18.5 \mathrm{pc}$, whereas CNP expression in embryos' trunks increases continuously until birth (Stepan et al. 2001). Although these alterations in CNP mRNA cannot be directly related to a physiological function during embryonic development, further studies investigating embryos deficient in, or overexpressing CNP will clarify this issue.

A recent study identified the human heart as a CNPproducing organ, at least in the pathophysiological condition of chronic heart failure (Kalra et al. 2003). Although $\mathrm{CNP}$ is not yet expressed in the heart of mouse and human embryos (Takahashi et al. 1992, Cameron et al. 1996), neonatal mice already show low cardiac CNP mRNA concentrations that increase up to eightfold in adult animals (Stepan et al. 2001). Thus, it seems unlikely that CNP is a physiologically relevant component of the cardiac NPS during fetal development and should be considered as an independent hormone within the NPS. Since Doi and co-workers could show that CNP expression is suppressed by the vascular endothelial growth factor (VEGF) (Doi et al. 1996) and is co-expressed with components of the VEGF system in embryoid bodies, an in vitro model of developing embryos (Doi et al. 1997), a role for CNP in vascular cell differentiation and vasculogenesis can be assumed. However, the antimitogenic and antiproliferative effect of CNP on cultured adult vascular cells (Furuya et al. 1991) has not been demonstrated in direct in vitro or in vivo assays using embryonic vascular cells or vascularization assays.

In human second trimester fetuses, CNP plasma concentrations could be measured after cordocentesis in normal fetuses, fetuses with rhesus isoimmunization before and after intravascular transfusion and fetuses with structural malformations (Stepan et al. 2000b). However, the source of CNP production in the human fetus remains to be elicited. In contrast to ANP and BNP (Walther et al. 2001), the fetal CNP plasma concentrations remain stable in the investigated fetal diseases and after volume load during intravascular transfusion. This could be expected because a long-term up-regulation of CNP would probably cause skeletal malformations as reported for mice with CNP overexpression ( $\mathrm{Y}$ Ogawa, personal communication). Moreover, fetal CNP plasma levels are higher than previously measured maternal concentrations, suggesting that the fetus expresses CNP independently from the maternal circulation (Stepan et al. 2000b). This is supported indirectly by the finding that ANP does not cross the placenta (Deloof et al. 1995). This has not yet been investigated for CNP but because of the structural homology within the natriuretic peptides one can expect that CNP also does not cross the placenta. This assumption and the finding of higher fetal CNP plasma concentrations compared with the maternal circulation indicate that the developing fetus is able to synthesize CNP de novo. 


\section{Transgenic animal models}

The generation of animal models with over-expression or disruption of genes has given further insight into the physiology of the NPS. The offspring of CNP-deficient mice show severe dwarfism due to impaired endochondral ossification. Neonatal mice are slightly growth retarded and show a high mortality, with $70 \%$ of the pups dying during the first 100 days (Chusho et al. 2001). However, surviving males and females are fertile. Up to now, a detailed histomorphological and endocrine analysis of reproductive tissues in these animals is still lacking. Transgenic animals over-expressing CNP also show bone malformations ( $\mathrm{Y}$ Ogawa, personal communication). Interestingly, investigation of the $N p p c-/-$ mice that lack the clearance receptor and mice over-expressing BNP also reveals typical signs of achondroplasia (Suda et al. 1998, Matsukawa et al. 1999, Chusho et al. 2000). While the clearance receptor deficiency leads to the elevation of CNP concentrations comparable to that in CNP-overexpressing mice, Chusho et al. (2000) demonstrated by cross breeding of the BNP model with GC-A-deficient mice that these malformations are mediated by an 'unspecific' BNP overstimulation of the GC-B receptor.

In conclusion, one of the major biological functions of CNP in the fetus is the regulation of bone growth via chondrocyte proliferation and cartilage matrix production (Mericq et al. 2000).

\section{Conclusions}

The recent literature and our own investigations on the role of C-type natriuretic peptide in reproduction, pregnancy and fetal development indicate mRNA expression in the reproductive target organs, its regulation under pathophysiological conditions and preliminary data for a distinct function of CNP in defined situations. Although the primary signaling pathway with the CNP/GC-B/ cGMP axis seems to be identified and is singular for this hormone, further investigations are needed to characterize intracellular signal cascades and CNP target genes to illustrate the importance of this third member of the NPS. However, the mechanisms by which CNP mediates its biological functions are multiple, and the inhibition of cell proliferation and differentiation and the vasorelaxant action serve only as two examples.

\section{References}

Acuff CG, Huang H \& Steinhelper ME 1997 Estradiol induces C-type natriuretic peptide gene expression in mouse uterus. American Journal of Physiology 273 H2672-H2677.

Borgeson DD, Stevens TL, Heublein DM, Matsuda Y \& Burnett JC 1998 Activation of myocardial and renal natriuretic peptides during acute intravascular volume overload in dogs: functional cardiorenal responses to receptor antagonism. Clinical Science 95 195-202.
Cameron VA, Aitken GD, Ellmers LJ, Kennedy MA \& Espiner EA 1996 The sites of gene expression of atrial, brain, and C-type natriuretic peptides in mouse fetal development: temporal changes in embryos and placenta. Endocrinology 137 817-824.

Carvajal JA, Aguan K, Thompson LP, Buhimschi IA \& Weiner CP 2001 Natriuretic peptide-induced relaxation of myometrium from the pregnant guinea pig is not mediated by guanylate cyclase activation. Journal of Pharmacology and Experimental Therapeutics 297 181-188.

Chen HH \& Burnett JC Jr 1998 C-type natriuretic peptide: the endothelial component of the natriuretic peptide system. Journal of Cardiovascular Pharmacology 32 22-28.

Chrisman TD, Schulz S, Potter LR \& Garbers DL 1993 Seminal plasma factors that cause large elevations in cellular cyclic GMP are C-type natriuretic peptides. Journal of Biological Chemistry 268 3698-3703.

Chusho H, Ogawa Y, Tamura N, Suda M, Yasoda A, Miyazawa T, Kishimoto I, Komatsu Y, Itoh H, Tanaka K, Saito Y, Garbers DL \& Nakao K 2000 Genetic models reveal that brain natriuretic peptide can signal through different tissue-specific receptor-mediated pathways. Endocrinology 141 3525-3526.

Chusho H, Tamura N, Ogawa Y, Yasoda A, Suda M, Miyazawa T, Nakamura K, Nakao K, Kurihara T, Komatsu Y, Itoh H, Tanaka K, Saito Y, Katsuki M \& Nakao K 2001 Dwarfism and early death in mice lacking C-type natriuretic peptide. PNAS 98 4016-4021.

Clavell AL, Stingo AJ, Wie CM, Heublein DM \& Burnett JC 1993 C-type natriuretic peptide: a selective cardiovascular peptide. American Journal of Physiology 264 R290-R295.

Deloof S, VanCamp G \& Chatelain A 1995 Absence of transplacental transfer of atrial natriuretic peptide in the rat: direct experimental evidence. Medical Science Research 23 347-350.

Doi K, Itoh H, Komatsu Y, Igaki T, Chun TH, Takaya K, Yamashita J, Inoue M, Yoshimasa T \& Nakao K 1996 Vascular endothelial growth factor suppresses C-type natriuretic peptide secretion. Hypertension. 27 811-815.

Doi K, Itoh $\mathrm{H}$, Nakagawa $\mathrm{O}$, Igaki $\mathrm{T}$, Yamashita J, Chun TH, Inoue M, Masatsugu K \& Nakao K 1997 Expression of natriuretic peptide system during embryonic stem cell vasculogenesis. Heart Vessels 12 $18-22$.

Dos Reis AM, Fujio N, Dam TV, Mukaddam-Daher S, Jankowski M, Tremblay J \& Gutkowska J 1995 Characterization and distribution of natriuretic peptide receptors in the rat uterus. Endocrinology 136 4247-4253.

Drewett JG, Fendly BM, Garbers DL \& Lowe DG 1995 Natriuretic peptide receptor-B (gyanylyl cyclase-B) mediates C-type natriuretic peptide relaxation of precontracted rat aorta. Journal of Biological Chemistry 270 4668-4674.

Furuya M, Yoshida M, Hayashi Y, Ohnuma N, Minamino N, Kangawa K \& Matsuo H 1991 C-type natriuretic peptide is a growth inhibitor of rat vascular smooth muscle cells. Biochemical and Biophysical Research Communications 177 927-931.

Ganguly A, Chiou S, West LA \& Davis JS 1989 Atrial natriuretic factor inhibits angiotensin-induced aldosterone secretion: not through cGMP or interference with phospholipase C. Biochemical and Biophysical Research Communications 28 148-154.

Guidone G, Muller D, Vogt K \& Mukhopadhyay AK 2002 Characterization of VIP and PACAP receptors in cultured rat penis corpus cavernosum smooth muscle cells and their interaction with guanylate cyclase-B receptors. Regulatory Peptides 108 63-72.

Hatjis CG \& Grogan DM 1988 Atrial natriuretic peptide receptors in normal human placentas. American Journal of Obstetrics and Gynecology 159 587-591.

Heublein DM, Clavell AL, Stingo AJ, Lerman A, Wold L \& Burnett JC 1992 C-type natriuretic peptide immunoreactivity in human breast vascular endothelial cells. Peptides 13 1017-1019.

Huang W, Lee D, Yang Z, Casley D, Throsby M, Copolov DL, Johnston C \& Lim AT 1992 Evidence for atrial natriuretic peptide-(5-28) production by rat placental cytotrophoblasts. Endocrinology 131 919-924. 
Huang H, Acuff CG \& Steinhelper ME 1996 Isolation, mapping, and regulated expression of the gene encoding mouse C-type natriuretic peptide. American Journal of Physiology 271 H1565-H1575.

Itoh H, Sagawa N, Hasegawa M, Nanno H, Kobayashi F, Ihara Y, Mori T, Komatsu Y, Suga S, Yoshimasa T, Itoh H \& Nakao K 1994 Expression of biologically active receptors for natriuretic peptides in the human uterus during pregnancy. Biochemical and Biophysical Research Communications 203 602-607.

Itoh H, Bird IM, Nakao K \& Magness RR 1998 Pregnancy increases soluble and particulate guanylate cyclases and decreases the clearance receptor of natriuretic peptides in ovine uterine, but not systemic, arteries. Endocrinology 139 3329-3341.

Jankowski M, Reis AM, Mukaddam-Daher S, Dam TV, Farookhi R \& Gutkowska J 1997 C-type natriuretic peptide and the guanylyl cyclase receptors in the rat ovary are modulated by the estrous cycle. Biology of Reproduction 56 59-66.

Kalra PR, Clague JR, Bolger AP, Anker SD, Poole-Wilson PA, Struthers AD \& Coats AJ 2003 Myocardial production of C-type natriuretic peptide in chronic heart failure. Circulation 107 571-573.

Kenny AJ, Bourne A \& Ingram J 1993 Hydrolysis of human and pig brain natriuretic peptides, urodilatin, C-type natriuretic peptide and some C-receptor ligands by endopeptidase-24-11. Biochemical Journal $29183-88$.

Kim SZ, Kim SH, Park JK, Koh GY \& Cho KW 1998 Presence and biological activity of C-type natriuretic peptide-dependent guanylate cyclase-coupled receptor in the penile corpus cavernosum. Journal of Urology 159 1741-1746.

Koller KJ \& Goeddel DV 1992 Molecular biology of the natriuretic peptides and their receptors. Circulation 86 1081-1088.

Komatsu Y, Nakao K, Suga S, Ogawa Y, Mukyama M, Arai H, Shirakami G, Hosoda K, Nakagawa O, Hama N, Kishimoto I \& Imura H 1991 C-type natriuretic peptide (CNP) in rats and humans. Endocrinology 129 1104-1106.

Küthe A, Reinecke M, Ückert S, Becker A, David I, Heitland A, Stief CG, Forssmann WG \& Mä gert HJ 2003 Expression of guanylyl B in the human corpus cavernosum penis and the possible involvement of its ligand C-type natriuretic polypeptide in the induction of penile erection. Journal of Urology 169 1918-1922.

Levin ER, Gardner DG \& Samson WK 1998 Natriuretic peptides. New England Journal of Medicine 339 321-328.

Maack T 1996 Role of atrial natriuretic factor in volume control. Kidney International 49 1732-1737.

Maack T, Suzuki M, Almeida FA, Nussenzveig D, Scarborough RM, McEnroe GA \& Lewicki JA 1987 Physiological role of silent receptors of atrial natriuretic factor. Science 238 675-678.

McGee E, Spears N, Minami S, Hsu SY, Chun SY, Billig H \& Hsueh AJ 1997 Preantral ovarian follicles in serum-free culture: suppression of apoptosis after activation of the cyclic guanosine $3^{\prime}, 5^{\prime}$-monophosphate pathway and stimulation of growth and differentiation by follicle-stimulating hormone. Endocrinology 138 2417-2424.

Matsukawa N, Grzesik WJ, Takahashi N, Pandey KN, Pang S, Yamauchi M \& Smithies O 1999 The natriuretic peptide clearance receptor locally modulates the physiological effects of the natriuretic peptide system. PNAS 96 7403-7408.

Mericq V, Uyeda JA, Barnes KM, De Luca F \& Baron J 2000 Regulation of fetal rat bone growth by C-type natriuretic peptide and cGMP. Pediatric Research 47 189-193.

Middendorff R, Muller D, Paust HJ, Holstein AF \& Davidoff MS 1997 New aspects of Leydig cell function. Advances in Experimental Medicine and Biology 424 125-138.

Middendorff R, Davidoff MS, Behrends S, Mewe M, Miethens A \& Muller D 2000 Multiple roles of the messenger molecule cGMP in testicular function. Andrologia 32 55-59.

Okahara K, Kambayashi J, Ohnishi T, Fujiwara Y, Kawasaki T \& Monden M 1995 Shear stress induces expression of CNP gene in human endothelial cells. FEBS Letters 373 108-110.
Prickett TCR, Yandle TG, Nicholls MG, Espiner EA \& Richards AM 2001 Identification of amino-terminal pro-C-type natriuretic peptide in human plasma. Biochemical and Biophysical Research Communications 286 513-517.

Stein BC \& Levin RI 1998 Natriuretic peptides: physiology, therapeutic potential, and risk stratification in ischemic heart disease. American Heart Journal 135 914-923.

Stepan H, Walther T, Walther D \& Faber R 1998a Detection of C-type natriuretic peptide in normal pregnancy. Journal of Perinatal Medicine 26 56-58.

Stepan H, Walther T \& Faber R 1998 b C-type natriuretic peptide in maternal plasma in spontaneous labour, at elective cesarean section and during puerperium. Journal of Perinatal Medicine 26 396-399.

Stepan H, Faber R, Walther D \& Walther T 1999 C-type natriuretic peptide levels in women with gestational hypertension and preeclampsia. Obstetrics and Gynecology 93 199-202.

Stepan H, Leitner E, Bader M \& Walther T 2000a Organ-specific mRNA distribution of C-type natriuretic peptide in neonatal and adult mice. Regulatory Peptides 95 81-85.

Stepan H, Walther D, Faber R \& Walther T $2000 b$ Detection of C-type natriuretic peptide in fetal circulation. Journal of Perinatal Medicine 28 118-121.

Stepan H, Leitner E, Walter K, Bader M, Schultheiss HP, Faber R \& Walther T 2001 Gestational regulation of the gene expression of C-type natriuretic peptide in mouse reproductive and embryonic tissue. Regulatory Peptides 102 9-13.

Stepan H, Faber R, Stegemann S, Schultheiss HP \& Walther T $2002 a$ Expression of C-type natriuretic peptide in human placenta and myometrium in normal pregnancies and pregnancies complicated by intrauterine growth retardation - preliminary results. Fetal Diagnosis and Therapy 17 37-41.

Stepan H, Faber R \& Walther T $2002 b$ Plasma levels and expression of C-type natriuretic peptide (CNP) in human placenta and myometrium in preeclampsia. Hypertension in Pregnancy 21 (Suppl 1) 117.

Suda M, Ogawa Y, Tanaka K, Tamura N, Yasoda A, Takigawa T, Uehira M, Nishimoto H, Itoh H, Saito Y, Shiota K \& Nakao K 1998 Skeletal overgrowth in transgenic mice that overexpress brain natriuretic peptide. PNAS 95 2337-2342.

Sudoh T, Minamino N, Kangawa K \& Matsuo H 1990 C-type natriuretic peptide $(\mathrm{CNP})$ : a new member of the natriuretic peptide family identified in the porcine brain. Biochemical and Biophysical Research Communications 168 863-870.

Takahashi T, Allen PD \& Izumo S 1992 Expression of A-, B-, and C-type natriuretic peptide genes in failing and developing human ventricles. Correlation with expression of the $\mathrm{Ca}(2+)$-ATPase gene. Circulation Research 71 9-17.

Totsune K, Takahashi K, Murakami O, Satoh F, Sone M, Saito T, Sasano H, Mouri T \& Abe K 1994 Natriuretic peptides in the human kidney. Hypertension 24 758-762.

Vatta MS, Presas MF, Bianciotti LG, Rodriguez-Fermepin M, Ambros R \& Fernandez BE 1997 B and C type natriuretic peptides modify norepinephrine uptake and release in the rat adrenal medulla. Peptides 18 1483-1489.

Walther T, Stepan H \& Faber R 2001 Dual natriuretic peptide response to volume load in the fetal circulation. Cardiovascular Research 49 817-819.

Walther T, Stepan H, Schultheiss HP \& Walther-Heringer S 2002 Opposite regulation of BNP levels in myometrium and placenta of preeclamptic patients. Hypertension in Pregnancy 21 (Suppl 1) 115.

Yoshimura M, Yasue H, Okumura K, Ogawa H, Jougasaki M, Mukoyama M, Nakao K \& Imura H 1993 Different secretion patterns of atrial natriuretic peptide and brain natriuretic peptide in patients with congestive heart failure. Circulation 87 464-469.

Received 18 July 2003

Accepted 16 October 2003 